\title{
Physical activity programs for elderly persons: an evaluation of Brazilian scientific production using the RE-AIM framework
}

\section{Abstract}

The RE-AIM framework is a model that analyzes both the external and internal validity of health programs. It proposes that programs should be evaluated based on five key dimensions: reach, effectiveness/efficiency, adoption, implementation and maintenance. The aim of the present study was to conduct a systematic review of physical activity programs for elderly persons published in Brazilian scientific literature using the REAIM framework. A total of 26 articles included in four scientific databases from 1993 to 2013 were identified and coded using a validated 52-item RE-AIM abstraction tool. Using the RE-AIM dimensions, indicators of reach (47.2\%), effectiveness (36.3\%), and implementation $(27.5 \%)$ were reported more often than indicators of adoption $(6.4 \%)$ and maintenance $(4.7 \%)$. Only two articles were included in all five RE-AIM dimensions. Despite the increasing number of interventions targeting the elderly, few address the dimensions proposed by the RE-AIM framework, reducing their potential generalizability outside their original settings, and their overall external validity.

\footnotetext{
Universidade Estadual do Sudoeste da Bahia, Departamento de Saúde I. Jequié, BA, Brasil.

2 Universidade Estadual do Sudoeste da Bahia, Departamento de Saúde II. Jequié, BA, Brasil.

3 Universidade Federal de Santa Catarina, Centro de Desportos, Programa de Pós-graduação em Educação Física. Florianópolis, SC, Brasil.

4 Departament of Human Nutrition, Foods, and Exercise da Virginia Tech, Blacksburg, VA, USA.
}

Funding support: Bahia State Research Support Foundation (Fundação de Amparo à Pesquisa do Estado da Bahia - Fapesb), Coordination of Superior Level Staff Improvement (Coordenação de Aperfeiçoamento de Pessoal de Nível Superior - CAPES) and Universidade Estadual do Sudoeste da Bahia, Interinstitutional Doctoral Course in Physical Education (PPGEF/UFSC - DCSAU/UESC).

Correspondence

Camila Fabiana Rossi Squarcini

E-mail: csquarcini@gmail.com
Camila Fabiana Rossi Squarcini'

Saulo Vasconcelos Rocha²

Hector Luiz Rodrigues Munaro'

Tânia Rosane Bertoldo Benedetti ${ }^{3}$

Fabio Araujo Almeida ${ }^{4}$

Key words: Physical Exercise; Elderly; Health. 


\section{INTRODUCTION}

Brazil's demographic profile reveals a largenumber of elderly persons, amounting to $10 \%$ of the country's total population according to the Synthesis of Social Indicators, with projections indicating a likely increase in that percentage to in excess of $22.7 \%$ by $2050 .^{2}$

In view of this demographic profile, there has been an observable increase in the number of scientific studies investigating the relationship between healthy ageing and regular physical activity. ${ }^{3,4}$ This increase can be credited to the fact that regular physical activity has positive effects on health and the prevention and control of chronic diseases such as diabetes mellitus type II, arterial hypertension and coronary artery disease, ${ }^{5-7}$ as well as aiding improvements in mental health ${ }^{8}$ and metabolic profile,${ }^{10}$ a reduction in cognitive decline ${ }^{9}$ and a reduction in mortality from noncommunicable diseases, ${ }^{6}$ cardiovascular diseasesand indeed from all causes. ${ }^{11}$

There are a growing number of studies regarding guided intervention in the practice of regular programs of physical activity for the elderly. These publications are characterized by being conducted in a clinical, controlled environment and with motivated participants. However, studiesthat report results concerning either the external or the internal validity of the programs are rare. ${ }^{12}$ Thisissuemust be investigatedif these programs are to be implemented in reality.

The RE-AIM model proposed by Glasgow et al. is an evaluation method that aims to analyze both the internal and external validity of health programs. ${ }^{13}$ This model has been used in literature as a means of evaluation for studies of the systematic review of scientific articles, as in works by Antikainen \& Ellis, ${ }^{12}$ Allen et al. ${ }^{14}$ and Kessler et al. ${ }^{15}$ It was recently translated and culturally adapted for the Brazilian context by Almeida et al. ${ }^{16}$

One characteristic of the RE-AIM model is itsbroad analysis of the impact of health promotion programs, evaluating the impact of a given activity in five dimensions: reach (absolute number and proportion of the targeted audience attended to, as well as therepresentation of this audience in the program andthe evaluation of its characteristics); efficiency/effectiveness (a final outcome of the program's implementation, where its positive and negative effects are checked along with quality of life and economic results); adoption (the number and profile of staff and practitioners and of the plans to be adopted in the intervention);implementation (faithfulness to the principles of the intervention shown on the part of organizations and subjects); and maintenance (how the program continues after its implementation - Glasgow et al.; ${ }^{13}$ Almeida et al. $\left.{ }^{16}\right)$.

Given the above, the aim of this paper was to carry out a systematic review, based on the REAIM model, of Brazilian scientific articles that utilized regular programs of physical activity for the elderly.

\section{MATERIALS AND METHOD}

In the selection of databases, those with the largest volumeof publications by Brazilian scientists were chosen. These were the following: PubMed, Virtual Health Library (VHL), SciELO and Scopus with a scope of January 1993 to August 2013 (the period in Brazil with the highest level of population aging $^{2}$ ).

Inthe selection of articles, the following descriptors were employed: motor activity, physical activity, locomotor activity, aged, elderly, intervention and Brazil,previously consulted in the Descriptors of Health Sciences (DeCS) and Medical Subject Headings (MeSH).Thus, the terms were combined as follows: motor activity OR physical activity OR locomotor activity AND aged OR elderly AND intervention AND Brazil.

The following were adopted as inclusion criteria: a) studies involving individuals aged 60 yearsor over; b) studies published between January 1993 
and August 2013; c) interventions involving regular programs of physical activity; d) articles published in English, Portuguese and/or Spanish; e) studies that applied some type of intervention (traditional or educational, for example) which involved the practice of regular programs of physical activity for the elderly. In terms of exclusion criteria, studies involving the following in their methodology were ruled out:meta-analysis, systematic review, literature review or observational study.

After a data search, as shown in Figure 1, 174 articles were found: 23 in VHL, 58 in PubMed, 19 in SciELO and 74 in Scopus. After reading of the titles,
51 were selected to have theirabstractsexamined. Of these, 26 articles were included for detailed reading based on the adopted inclusion criteria. The selection of articleswas madeafterseparate analysis by three evaluators, withthe agreement of at least two required before an article was chosen.

The principalexclusion criteriathat resulted in the removal of most studies were: duplicate studies across two or more databases, observational studies and studies based onsystematic review, meta-analysis or literature review.Accordingly, a total of 20 articles published in VHL, 45 from PubMed, 9 from SciELO and 73 from Scopus were excluded, as shown in Figure 1.

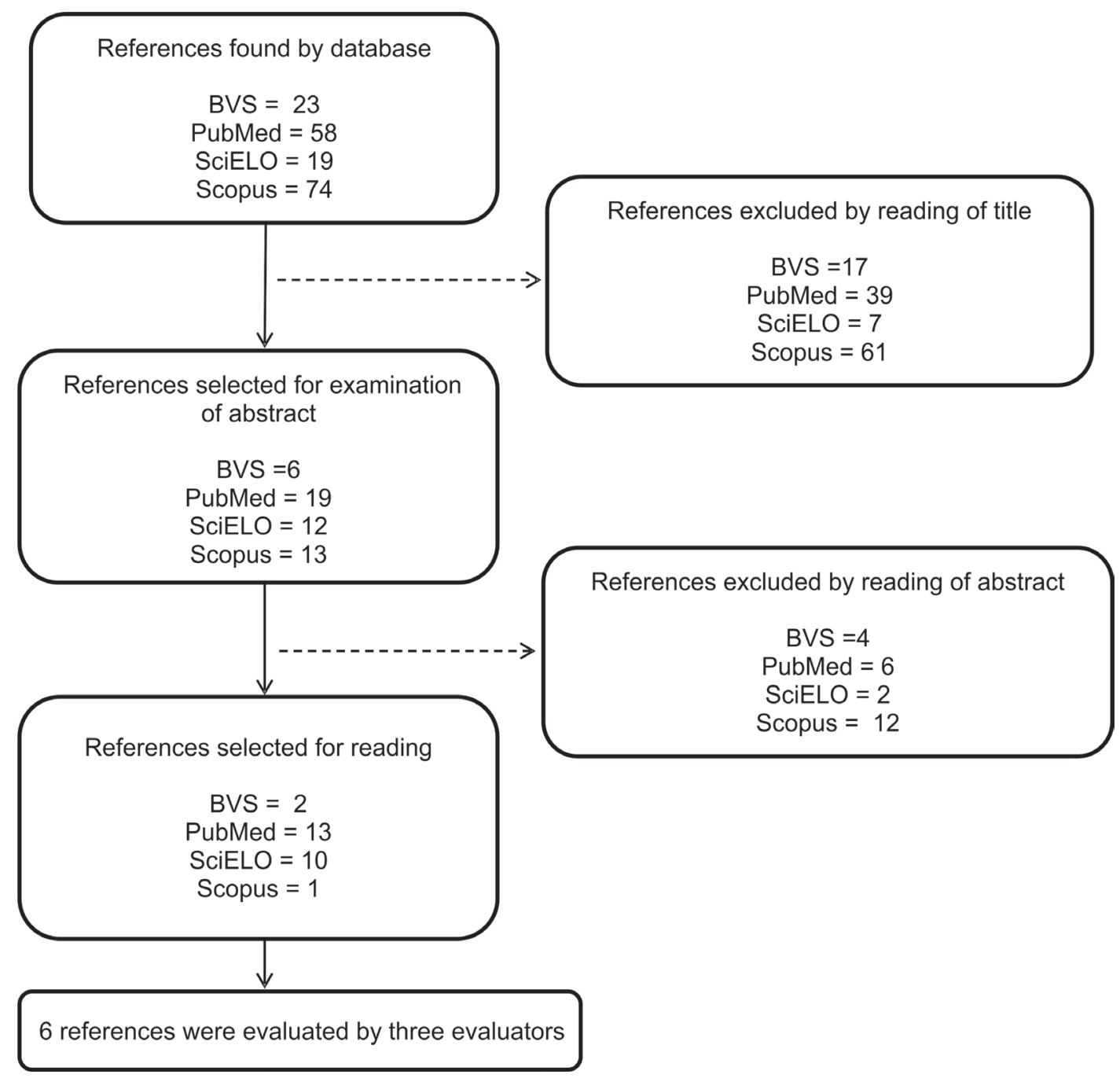

Figure 1. Flowchart of the article selection process for the period 1993-2013. Jequié, BA, 2014. 
For analysis of the 26 articles, the codifying tool previously validated by Arkers et al. was used, with its aim being to evaluate the five dimensions of RE-AIM model:reach, effectiveness/efficiency, adoption, implementation and maintenance. The method used for the selection of articles was also adopted for this codifying process. For analysis of the data, descriptive statistic procedures (single frequency, percentage) were employed using theSPSS 16.0 program.

\section{RESULTS}

The 26 articles demonstrated a certain tendency, as shown in Table 1. With a mean age of 69.45 $( \pm 6.33)$ years and great variability in the number of individuals (a minimum of eight and a maximum of 100 participants). The majority of the studies were of a quantitative variety, utilized a control group in an experimental model, weredeveloped in controlled environments (laboratories and/or universities) and came from the southeast region of the country(the most economically developed area of Brazil).

Table 1. Details of the scientific articles analyzed. Jequié, BA, 2014.

\begin{tabular}{|c|c|c|c|c|c|}
\hline Author & Type of study & $\begin{array}{l}\text { Control } \\
\text { Group }\end{array}$ & $\mathrm{n}$ & $\begin{array}{l}\text { Study } \\
\text { location }\end{array}$ & $\begin{array}{l}\text { Study } \\
\text { region }\end{array}$ \\
\hline Benedetti et al. $(2012)^{18}$ & Quantitative-Qualitative & Yes & 100 & Community & South \\
\hline Bonganha et al.(2012) & Quantitative & Yes & 32 & University & Southeast \\
\hline Burke et al. $(2010)^{20}$ & Quantitative & Yes & 33 & University & Southeast \\
\hline Canonici et al.(2012) $)^{21}$ & Quantitative & Yes & 32 & Laboratory & Southeast \\
\hline Caromano et al. $(2006)^{22}$ & Quantitative & Yes & 20 & Laboratory & Southeast \\
\hline Castro et al.(2007) & Quantitative & No & 70 & Community & Southeast \\
\hline Cavalcante et al.(2011) ${ }^{24}$ & Qualitative & No & 18 & Community & Northeast \\
\hline De Araújo et al.(2013) ${ }^{25}$ & Quantitative & Yes & 28 & Community & Centre-west \\
\hline Fernandes et al. $(2012)^{26}$ & Quantitative & No & 8 & - & Northeast \\
\hline Ferreira et al. $(2008)^{27}$ & Quantitative & No & 401 & Community & Southeast \\
\hline Fonseca et al.(2012) ${ }^{28}$ & Quantitative-Qualitative & No & 21 & Community & Southeast \\
\hline Gobbi et al.(2009) ${ }^{29}$ & Quantitative & No & 34 & Laboratory & Southeast \\
\hline Hernandez et al. $(2010)^{30}$ & Quantitative & Yes & 16 & Laboratory & Southeast \\
\hline Ide et al. $(2005)^{31}$ & Quantitative & Yes & 59 & University & South \\
\hline Lustosa et al. $(2011)^{32}$ & Quantitative & Yes & 32 & - & Southeast \\
\hline Lustosa et al. $(2013)^{33}$ & Quantitative & Yes & 32 & Laboratory & Southeast \\
\hline Machado et al. $(2013)^{34}$ & Quantitative & No & 20 & Community & Southeast \\
\hline Nascimento et al. $(2013)^{35}$ & Quantitative & Yes & 42 & Laboratory & Southeast \\
\hline Raso et al. $(2007)^{36}$ & Quantitative & No & 14 & Laboratory & Southeast \\
\hline Renno et al. $(2005)^{37}$ & Quantitative & No & 20 & Community & Centre-west \\
\hline Sá et al. $(2012)^{38}$ & Quantitative & Yes & 32 & Laboratory & Southeast \\
\hline Santana et al. $(2012)^{39}$ & Quantitative & Yes & 32 & Laboratory & Southeast \\
\hline Stella et al. $(2011)^{40}$ & Quantitative & Yes & 20 & Laboratory & Southeast \\
\hline Tanaka et al. $(2009)^{41}$ & Quantitative & No & 94 & Laboratory & Southeast \\
\hline Ueno et al. $(2012)^{42}$ & Quantitative & Yes & 27 & Laboratory & Southeast \\
\hline Vale et al. $(2009)^{43}$ & Quantitative & Yes & 35 & University & Northeast \\
\hline
\end{tabular}


Reach

After a review of the literature, we found that an average of $47.2 \%$ of the reach indicators were presentinthe studies evaluated. Among the categories evaluated "sample size" (100\%), "inclusion criteria" (96.2\%) and "exclusion criteria" $(96.2 \%)$ were the most reported. In contrast, the "cost of recruitment of participants" and "use of qualitative criteria for measuring reach" indicators were not reported in any of the evaluated studies (Table 2).

Table 2. Indicators for the reach dimension from the RE-AIM model of the analyzed studies. Jequié, BA, 2014.

\begin{tabular}{lc}
\hline \multicolumn{1}{c}{ Reach } & $\%$ \\
\hline Description of the target population & 30.8 \\
Demographic and behavioral information regarding the target population & 26.9 \\
Method of identification of the target population & 50.0 \\
Recruitment strategies & 42.3 \\
Inclusion criteria & 96.2 \\
Exclusion criteria & 96.2 \\
Number of personseligible forand invitedto recruitment & 42.3 \\
Sample size & 100 \\
Participation rate & 34.6 \\
Cost of recruitment & 0 \\
Use of qualitative methods to assess reach & 0 \\
\hline
\end{tabular}

Effectiveness/Efficiency

On average, $36.9 \%$ of the indicators of effectiveness/efficiency were present, with $100 \%$ of the studies providing "reports of the primary results" and a "report of the mediators," but none providing information regarding the "negative consequences" and "cost-effectiveness" categories (table 3).

Table 3. Indicators for the effectiveness/efficiency dimension from the RE-AIM model of the studies analyzed. Jequié, BA, 2014.

\begin{tabular}{lc}
\hline \multicolumn{1}{c}{ Effectiveness/Efficiency } & $\%$ \\
\hline Report of primary results & 100 \\
Report of mediators & 100 \\
Report ofmoderators & 24.0 \\
Intention of treatment or monitoring & 26.9 \\
Quality of life measurements & 26.9 \\
Measurement of unintended consequences (negative) in the results & 0 \\
Percentage of dropouts (at the program's conclusion) & 34.6 \\
Cost-effectiveness & 0 \\
Use of qualitative methods to assess the effectiveness/efficiency & 20.0 \\
\hline
\end{tabular}


Adoption

Adoption was analyzed both at an organizational level and at a staff level. A limited percentage of articles $(n=10)$ met at least one of the adoption criteria, with on average $7.6 \%$ of the organizational adoption indicators and $4.9 \%$ of staff adoption indicators being attended to. In terms of the evaluation of adoption at the organizational level, the most frequently cited categories were "number of participants" (19.2\%) and "description of the target site" (15.4\%); at the group levelthe category "staff training" (18.7\%) was that referred to most among the studies analyzed. However, the categories of "participation rate" and "measurement of adoption cost" were not cited in any of the studies (Table 4).

Table 4. Indicators for the adoption dimension from the RE-AIM model of the analyzed studies. Jequié, BA, 2014.

\begin{tabular}{lc}
\hline \multicolumn{1}{c}{ Organizational Level } & $\%$ \\
\hline Number of persons eligible and invited & 3.8 \\
Number ofparticipants & 19.2 \\
Participation rate & 0 \\
Description of the target site & 15.4 \\
Criteria for inclusion/exclusion of scenarios & 7.7 \\
Description of the site of the intervention & 7.7 \\
Method of identification of the scenario & 7.7 \\
Average number of people served by the scenario & 0 \\
\hline \multicolumn{1}{c}{ Staff Level } & 3.8 \\
\hline Number of persons eligible and invited & 7.7 \\
Members of the total group who agreed to participate & 0 \\
Participation rate & 3.8 \\
Method for identification of the delivery agent to the destination & 15.4 \\
Agent's knowledge level & 3.8 \\
Criteria for inclusion/exclusion of agents & 0 \\
Measurement of adoption cost & \\
\hline
\end{tabular}

Implementation

Findings regarding the extent of implementation of the programs indicated that $27.5 \%$ of the indicators were reported in the studies. The "number of intervention contacts" (76.9\%), the "period of contacts" (68\%) and the "duration of contacts" $(60 \%)$ were the most cited categories. The category "consistency in implementation across scenarios and enforcement officers" was not reported in any study (Table 5).

\section{Maintenance}

Maintenance was the least reported dimension across the studies analyzed, with on average only $4.7 \%$ of its indicators reported. When analyzing this category at its two levels (individual and organizational), it was found that $10.3 \%$ of studies reported information regarding maintenance at an individual level (most cited category: "dropouts", at $15.4 \%$ and $1.9 \%$ regarding maintenance at the organizational level (table 6). 
Table 5. Indicators for the implementation dimension from the RE-AIM model of the analyzed studies. Jequié, BA, 2014.

\begin{tabular}{lc}
\hline \multicolumn{1}{c}{ Implementation } & $\%$ \\
\hline Theories & 7.7 \\
Number of contacts of the intervention & 76.9 \\
Period of the contacts & 68.0 \\
Durationof the contacts & 60.0 \\
Measure of whether the protocol was performed as expected & 3.8 \\
Consistency in implementation across scenarios and enforcement officers & 0 \\
Rates of attendance/completion of the participants & 19.2 \\
Measures of cost & 3.8 \\
Use of qualitative methods to measure implementation & 7.7 \\
\hline
\end{tabular}

Table 6. Indicators for the maintenance dimension from the RE-AIM model of the analyzed studies. Jequié, BA, 2014.

\begin{tabular}{lc}
\hline \multicolumn{1}{c}{ Maintenance } & Individual Level \\
\hline $\begin{array}{l}\text { Was individual behavior evaluated at some point after the intervention's completion? } \\
\text { (duration of observation) } \\
\text { Drop outs }\end{array}$ & 7.7 \\
Use of qualitative methods to assess individual maintenance & 15.4 \\
\hline \multicolumn{1}{c}{ Organizational Level } & 7.7 \\
\hline Report regarding alignment with the organization's mission & 3.8 \\
Is the program still in operation? $\quad 3.8$ \\
If no: Reasons for discontinuation $\quad 0$ \\
If yes: was the program has been modified? Be specific \\
Was the program institutionalized? \\
Waste
\end{tabular}

By individually examiningthe studies, as shown in Table 7, it was found that 11 articles attended to more than $50 \%$ of the reachcategories, while only three attended to more than $50 \%$ from the effectiveness/efficiency dimension. It should be noted that: a) in the dimension of adoption at organizational level, eight articles attended to at least one element of the checklist, with an emphasis onthe study by Benedetti et al. which included $75 \%$ of the items proposed in the RE-AIM model; b) in the dimension ofadoption at staff level,only four studies presented an affirmative question; c) in the dimension of implementation, most studies referred to only three of the nine analysis items; $d$ ) in the dimension of maintenanceon an individual level, the study by Caromano et al. study stood out, ${ }^{22}$ presenting $100 \%$ of the items; e) in themaintenance dimension, only the study by Benedetti et al. ${ }^{18}$ included the organizational level,attending to $50 \%$ of the total codification items. Thus, it was observed that the study by Benedetti et al. ${ }^{18}$ best attended the RE-AIM model, referring to 35 items $(66 \%)$ of 
the model's codification list, ${ }^{17,44}$ and indeed in its reachutilized part of this model. The study by Gobbi et al. ${ }^{29}$ least attended to the codification evaluated, with reference made to just seven categories.

Table 7. Detailing the percentage per article of conformity to the dimensions of the RE-AIM model. Jequié, BA, 2014.

\begin{tabular}{|c|c|c|c|c|c|c|c|}
\hline References & $\mathrm{R}(\%)$ & $\mathrm{E}(\%)$ & Ao $(\%)$ & As $(\%)$ & I (\%) & $\operatorname{Mi}(\%)$ & Mo $(\%)$ \\
\hline Benedetti et al. $(2012)^{18}$ & 63.6 & 66.7 & 75.0 & 71.4 & 66.7 & 66.7 & 50.0 \\
\hline Bonganha et al. $(2012)^{19}$ & 45.5 & 33.3 & 0 & 0 & 33.3 & 0 & 0 \\
\hline Burke et al.(2010) & 54.6 & 44.4 & 12.5 & 0 & 33.3 & 0 & 0 \\
\hline Canonici et al.(2012) & 27.3 & 33.3 & 0 & 0 & 44.4 & 0 & 0 \\
\hline Caromano et al. $(2006)^{22}$ & 27.3 & 33.3 & 0 & 0 & 0 & 100 & 0 \\
\hline Castro et al. $(2007)^{23}$ & 45.5 & 33.3 & 0 & 0 & 11.1 & 0 & 0 \\
\hline Cavalcante et al.(2011) & 45.5 & 55.6 & 0 & 0 & 22.2 & 0 & 0 \\
\hline De Araújo et al.(2013) ${ }^{25}$ & 36.4 & 22.2 & 0 & 0 & 33.3 & 0 & 0 \\
\hline Fernandes et al. $(2012)^{26}$ & 36.4 & 33.3 & 0 & 0 & 44.4 & 0 & 0 \\
\hline Ferreira et al. $(2008)^{27}$ & 81.8 & 44.4 & 12.5 & 14.3 & 22.2 & 66.7 & 0 \\
\hline Fonseca et al.(2012) & 63.6 & 33.3 & 0 & 0 & 0 & 0 & 0 \\
\hline Gobbi et al.(2009) ${ }^{29}$ & 9.1 & 22.2 & 12.5 & 0 & 33.3 & 0 & 0 \\
\hline Hernandez et al.(2010) & 36.4 & 33.3 & 0 & 0 & 11.1 & 0 & 0 \\
\hline Ide et al.(2005) & 54.6 & 44.4 & 12.5 & 0 & 33.3 & 0 & 0 \\
\hline Lustosa et al.(2011) ${ }^{32}$ & 54.6 & 33.3 & 12.5 & 0 & 33.3 & 0 & 0 \\
\hline Lustosa et al.(2013) ${ }^{33}$ & 27.3 & 22.2 & 0 & 0 & 33.3 & 0 & 0 \\
\hline Machado et al.(2013) & 72.7 & 66.7 & 50.0 & 0 & 0 & 0 & 0 \\
\hline Nascimento et al.(2013) & 54.6 & 33.3 & 0 & 0 & 11.1 & 0 & 0 \\
\hline Raso et al. $(2007)^{36}$ & 45.5 & 33.3 & 0 & 0 & 33.3 & 0 & 0 \\
\hline Renno et al.(2005) & 81.8 & 33.3 & 0 & 0 & 22.2 & 0 & 0 \\
\hline Sá et al.(2012) & 54.6 & 44.4 & 12.5 & 28.6 & 33.3 & 0 & 0 \\
\hline Santana et al. $(2012)^{39}$ & 36.4 & 22.2 & 0 & 0 & 22.2 & 0 & 0 \\
\hline Stella et al. $(2011)^{40}$ & 36.4 & 44.4 & 0 & 0 & 33.3 & 33.3 & 0 \\
\hline Tanaka et al.(2009) ${ }^{41}$ & 36.4 & 33.3 & 0 & 14.3 & 44.4 & 0 & 0 \\
\hline Ueno et al. $(2012)^{42}$ & 54.6 & 22.2 & 0 & 0 & 11.1 & 0 & 0 \\
\hline Vale et al. $(2009)^{43}$ & 27.3 & 33.3 & 0 & 0 & 33.3 & 0 & 0 \\
\hline Total (\%) & 46.5 & 36.8 & 7.7 & 5.0 & 26.9 & 10.3 & 1.9 \\
\hline
\end{tabular}

$\mathrm{R}=$ reach; $\mathrm{E}=$ efficiency/effectiveness; $\mathrm{Ao}=$ adoption - organizational level; As = adoption - team;

$\mathrm{I}=$ implementation; $\mathrm{Mi}=$ maintenance - individual level $; \mathrm{Mo}=$ maintenance - organizational level 


\section{DISCUSSION}

A high percentage of Brazilian studies presented interventions based onregular programs of physical activity for the elderly.These are studies of a quantitative nature,predominantlyfeaturing traditional interventions with a control group design which, in the majority of cases, demonstrated the effectivenessof the programs in terms ofimprovements made in aspects of physical fitness, for example, cardiorespiratory improvement, ${ }^{39}$ improved muscle strength ${ }^{33}$ and posturalimprovement among elderly persons with osteoporosis. ${ }^{20}$

Other common characteristics featured in themajority of the studies includedthe strict control of variables, since the majoritywere carried out in laboratories or universities, and sample homogeneity, with the aim of ensuring the programs' internal validity. ${ }^{45}$ However, due to this reductionist characteristic for the control of variables, this type of study is difficult to reproduce in reality. ${ }^{45,46} \mathrm{This}$ is one of the reasons whythe studies tentatively contemplated the items proposed in the codification of the RE-AIM model, especially with regard to the adoption and maintenance dimensions. Antikainen \& Ellis ${ }^{12}$ pointed out that few physical activity intervention programs include the dimensions proposed in the RE-AIM framework, and information regarding the external validity of these studies is scarce.

Among the studies analyzed, thatby Benedetti et al. ${ }^{18}$ best attended the five dimensions of the RE-AIM model(despite only referring to $66 \%$ of the total categories), featuring dialogue regarding both quantitative and qualitative measures, with execution occurring in the community itself.

It is worth noting that the reach dimension $(46.5 \%)$ was better attended than that of effectiveness/efficiency (36.8\%), since most of the research analyzed came from a position of reductionist scientific logic. ${ }^{45,46}$ However, as a resultof this inversion, issues such asthe qualitative method, unintended outcomes and cost-effectiveness are little discussed, in line with the scientific proposals adopted by most of the researchers. This data contrasts with the analysis of programs that utilize interventionsusingthe theories based onphysical activity conducted by Antikainen \& Ellis, ${ }^{12}$ or in other words, the studies analyzed by the authors reported more informationregarding the effectiveness/efficiency of interventions, even if on a superficial level, than of theirreach.

There is also the fact that the studies did not show figures for the cost-effectiveness of the program in any dimension, with the exception ofthe study by Benedetti et al., ${ }^{18}$ which attended to the "Cost Measures" categoryin the implementation dimension.The cost-effectiveness relationship is an important element for interventions that are incorporated into the BrazilianSistema Único de Saúde("Unified Health System"), ${ }^{47}$ in which funding acts as a major constraint to the effectiveness of public policies.For Silva ${ }^{47}$ the ideal scenario for public health in Brazil is to strike a balance between the effectiveness of a program and its cost, with the technique with thehighest level of effectiveness and lowest level of cost being chosen.

It should alsobe noted that while the present study aims to initiate discussion regarding the reality ofBrazilian studies of intervention programs through regular programs of physical activity for the elderly, it possesses some limitations. These includea) analysis of the programs using the REAIM model was conducted usingthe reports of the articles. In this case, it is possible that these articles are part of a larger study and, therefore, may not reflect the entire research project; and b) the restriction on the number of databases selected. The selection,made from just four databases, may not have incorporatedstudies which presentedexternal validation, for example.

However,despite these limitations, the results yielded were similar to those from other studies conducted with different populations ${ }^{12,14}$ in which the adoption and maintenance dimensions were also little reported. 


\section{CONCLUSION}

It appears that articles regarding the intervention of regular programs of physical activity for the elderly in Brazil have advanced from the point of view of understanding their effects on a homogeneous group. However, observing each dimension of the RE-AIM model, it was found that less than $50 \%$ of the categories from each dimension were attended to by the articles. These findings are reflected in the impracticality of other researchers or organs reproducing these physical activity programs.
Accordingly, there is a notable lacuna in Brazilian scienceas regards the study of dissemination and implementation of programs of physical activity for the elderly, and therefore studies aimed at ensuring the development of common practices and policies should be encouraged, thus ensuring the publication of externally validated studies, facilitating an expansionin the analysis of interventions aimed at the incorporation of these interventions in different contexts.

\section{REFERENCES}

1. Closs VE, Schwanke CHA. Aging index development in Brazil, regions, and federative units from 1970 to 2010. Rev Bras Geriatr Gerontol 2012;15(3):443-58.

2. Instituto Brasileiro de Geografia e Estatística, Diretoria de Pesquisas, Coordenação de População e Indicadores Sociais. Síntese de Indicadores Sociais: uma análise das condições de vida da população brasileira 2013. Rio de Janeiro: IBGE; 2013. (Estudos e Pesquisas); (Informação Demográfica e Socioeconômica, n. 32).

3. Maki Y, Ura C, Yamaguchi T, Murai T, Isahai M, Kaiho A, et al. Effects of intervention using a community-based walking program for prevention of mental decline: a randomized controlled trial. J Am GeriatrSoc 2012;60(3):505-10.

4. American College of Sports Medicine; ChodzkoZajko WJ, Proctor DN, Fiatarone Singh MA, Minson CT, Nigg CR, et al. American College of Sports Medicine position stand. Exercise and physical activity for older adults. Med Sci Sports Exerc 2009;41(7):1510-30.

5. Reiner M, Niermann C, Jekauc D, Woll A. Longterm healthy benefits of physical activity: a systematic review of longitudinal studies. BMC Public Health 2013;13(1):813-22.

6. Lee IM, Shiroma EJ, Lobelo F, Puska P, Blair SN. Impact of physical inactivity on the world's major non-communicable diseases. Lancet 2012;380(9838):219-29.

7. Nelson ME, Rejeski WJ, Blair SN, Duncan PW, Judge JO, King AC, et al. Physical and public health in older adults: recommendation from the American College of Sports Medicine and the American Heart Association. Med Sci Sports Exerc 2007;39(8):1435-45.
8. Patel A, Keogh JW, Kolt GS, Schofiled GM. The long-term effects of a primary care physical activity intervention on mental health in low-active, community-dwelling older adults. Aging Ment Health 2013;17(6):766-72.

9. Franco-Martín M, Parra-Vidales E, GonzálezPalau F, Bernate-Navarro M, Solis A. The influence of physical exercise in the prevention of cognitive deterioration in the elderly: a systematic review. Rev Neurol 2013;56(11):545-54.

10. Alves ES, Souza HS, Rosa JP, Lira FS, Pimentel GD, Santos RV, et al. Chronic exercise promotes alterations in the neuroendocrine profile of elderly people. HormMetabol Res 2012;44(13):975-9.

11. Park C, Lee J, Kang DY, Rhee CW, Park BJ. Indoor physical activity reduces all-cause and cardiovascular disease mortality among elderly women. J Prev Med Public Health 2012;45(1):21-8.

12. Antikainen I, Ellis R. A RE-AIM evaluation of theory-based physical activity interventions. J Sport ExercPsychol 2011;33(2):198-214.

13. Glasgow RE, Vogt TM, Boles SM. Evaluating the public health impact of health promotion interventions: the RE-AIM framework. Am J Public Health 1999;89(9):1322-7.

14. Allen K, Zoellner J, Motley M, Estabrooks PA. Understanding the internal and external validity of health literay interventions: a systematic literature review using the RE-AIM framework. J Health Commun 2011;16(Suppl 3):55-72.

15. Kessler RS, Purcell EP, Glasgow RE, Klesges LM, Benkeser RM, Peek CJ. What Does It Mean to "Employ" the RE-AIM Model? Eval Health Prof 2012;36(1):44-66. 
16. Almeida FA, Brito FA, Estabrooks PA. Modelo REAIM: tradução e adaptação cultural para o Brasil. REFACS 2013;1(1):6-16.

17. Akers J, Estabrooks PA, Davy BM. Translational research: bridging the gap between long-term weight loss maintenance research and practice. J Am Diet Assoc 2010;110(10):1511-22.

18. Benedetti TRB, Schwingel A, Gomez LSR, Chodzko-Zajko W. Programa "VAMOS" (Vida Ativa Melhorando a Saúde): da concepção aos primeiros resultados. Rev Bras CineantropomDesempenho Hum 2012;14(6):723-37.

19. Bonganha V, Modeneze DM, Madruga VA, Vilarta R. Effects of resistance training (RT) on body composition, muscle strength and quality of life (QoL) in post menopausal life. Arch GerontolGeriatr 2012;54(2):361-5.

20. Burke TN, França FJ, Ferreira de Meneses SR, Cardoso VI, Marques AP. Postural Control in Elderly persons with osteoporosis: efficacy of an intervention program to improve balance and muscle strength: a randomized controlled trial. Am J Phys Med Rehabil 2010;89(7):549-56.

21. Canonici AP, Andrade LP, Gobbi S, Santos-Galduroz RF, Gobbi LT, Stella F. Functional dependence and caregiver burden in Alzheimer's disease: a controlled trial on the benefits of motor intervention. Psychogeriatrics2012;12(3):186-92.

22. Caromano FA, Ide MR, Kerbauy RR. Manutenção na prática de exercícios por idosos. Rev Dep PsicolUfF 2006;18(2):177-92.

23. Castro PC, Tahara N, Rebelatto JR, Driusso P, Aveiro $\mathrm{MC}$, Oishi J. Influência da universidade aberta da terceira idade (UATI) e do programa de revitalização (REVT) sobre a qualidade de vida de adultos de meiaidade e idosos. Braz J Phys Ther2007;11(6):461-7.

24. Cavalcante CL, Gonçalves MC, Cavalcanti AL, Da Costa SF, Asciutti LS. Nutritional intervention program associated with physical activity: discourse of obese elderly women. CiêncSaúdeColetiva 2011;16(5):2383-90.

25. De Araújo TB, De Oliveira RJ, Martins WR, De Moura Pereira M, Copetti F, Safons MP. Effects of hippotherapy on mobility, strength and balance in elderly. Arch GerontolGeriatr 2013;56(3):478-81.

26. Fernandes AMBL, Ferreira JJA, Stolt LROG, De Brito GEG, Clementino ACCR, De Sousa NM. Efeitos da prática de exercício físico sobre o desempenho da marcha e da mobilidade funcional em idosos. FisioterMov 2012;25(4):821-30.

27. Ferreira SR, Gimeno SG, Hirai AT, Harima H, Matsumura L, Pittito BA. Effects of an intervention in eating habits and physical activity in JapaneseBrazilian women with a high prevalence of metabolic syndrome in Bauru, São Paulo State, Brazil. Cad SaúdePública 2008;24(Supl 2):294-302.

28. Fonseca CC, Gama EF, Thurm BE, Pereira ES, Limongelli AMA, Miranda MLJ. Benefícios da estimulação perceptual corporal no esquema corporal de idosos. Rev Bras GeriatrGerontol 2012;15(2):353-64.

29. Gobbi LT, Oliveira-Ferreira MD, Caetano MJ, Lirani-Silva E, Barbieri FA, Stella F, et al. Exercise programs improve mobility and balance in people with Parkinson's disease. Parkinsonism RelatDisord 2009;15(Suppl 3):49-52.

30. Hernandez SSS, Coelho FGM, Gobbi S, Stella F. Efeitos de um programa de atividade física nas funções cognitivas, equilíbrio e risco de quedas em idosos com demência de Alzheimer. Braz J Phys Ther2010;14(1):68-74.

31. Ide MR, Belini MA, Caromano FA. Effects of an aquatic versus non-aquatic respiratory exercise program on the respiratory muscle strength in healthy aged persons. Clinics 2005;60(2):151-8.

32. Lustosa LP, Silva JP, Coelho FM, Pereira DS, Parentoni AN, Pereira LS. Impact of resistance exercise program on functional capacity and muscular strength of knee extensor in pre-frail communitydwelling older women: a randomized crossover trial. Braz J Phys Ther 2011;15(4):318-24.

33. Lustosa LP, Máximo Pereira LS, Coelho FM, Pereira DS, Silva JP, Parentoni AN, et al. Impact of an Exercise Program on Muscular and Functional Performance and Plasma Levels. Arch Phys Med Rehabil 2013;94(4):660-6.

34. Machado CH, Do Carmo AS, Horta PM, Lopes ACS, Dos Santos LC. Efetividade de uma intervenção nutricional associada à prática de atividade física. Cad SaúdePública2013;21(2):148-53.

35. Nascimento CMC, Ayan C, Cancela JM, Pereira JR, De Andrade LP, Garuffi M, et al. Exercícios físicos generalizados capacidade funcional e sintomas depressivos em idosos brasileiros. RevBrasCineantropom Desempenho Hum 2013;15(4):486-97.

36. Raso V, Benard G, Silva Duarte AJS, Naale VM. Effect of resistance training on immunological parameters of healthy elderly women. Med Sci Sports Exerc 2007;39(12):2152-9.

37. Renno ACM, Granito RN, Driusso P, Costa $\mathrm{D}$, Oishi J. Effects of an exercise program on respiratory function, posture and on quality of life in osteoporotic women: a pilot study. Physiotherapy 2005;91(2):113-8. 
38. Sá AC, Bachion MM, Menezes RL. Physical exercises to prevent falls: a clinical trial with institutionalized elderly in the city of Goiânia in Brazil. CiêncSaúdeColetiva 2012;17(8):2117-27.

39. Santana MG, De Lira CA, Passos GS, Santos CA, Silva $\mathrm{AH}$, Yosjida $\mathrm{CH}$, et al. Is the six-minute walk test appropriate for detecting changes in cardiorespiratory fitness in healthy elderly men? J Sci Med Sport 2012;15(3):259-65.

40. Stella F, Canonici AP, Gobbi S, Galduroz RF, Cação JC, Gobbi LT. Attenuation of neuropsychiatric symptoms and caregiver burden in Alzheimer's disease by motor intervention: a controlled trial. Clinics2011;66(8):1353-60.

41. Tanaka K, Quadros AC Jr, Santos RF, Stella F, Gobbi LT, Gobbi S. Benefits of physical exercise on executive functions in older people with Parkinson's disease. Brain Cogn 2009;69(2):435-41.

42. Ueno DT, Gobbi S, Teixeira CVL, Sebastião E, Prado AKG, Costa JLR, et al. Efeitos de três modalidades de atividade física na capacidade funcional de idosos. RevBrasEducFísEsp 2012;26(2):273-81.
43. Vale RG, De Oliveira RD, Pernambuco CS, Meneses YP, Novaes JS, De Andrade AF. Effects of muscle strength and aerobic training on basal serum levels of IGF-1 and cortisol in elderly women. Arch GerontolGeriatr 2009;49(3):343-7.

44. RE-AIM working group [Internet]. Virginia: Virginia Tech; 2015. Adaptação do RE-AIM workinggroup; [acesso em 13 nov 2014]; [aproximadamente 2 telas]. Disponívelem: www.re-aim.org

45. Glasgow RE. What types of evidence are most needed to advance behavioral medicine? Ann Behav Med 2008;35(1):19-25.

46. Glasgow RE, Lichtenstein E, Marcus AC. Why don't we see more translation of healthy promotion research to practice?: rethinking the efficacy-to-effectiveness transition. Am J Public Health 2003;93(8):1261-7.

47. Silva LK. Avaliação tecnológica e análise custoefetividade em saúde: a incorporação de tecnologias e a produção de diretrizes clínicas para o SUS. CiêncSaúdeColetiva 2003;8(2):501-20. 